\title{
FUNCTIONAL AND STRUCTURAL OF THE ERECTOR \\ SPINAE MUSCLE DURING ISOMETRIC LUMBAR EXTENSION
}

\author{
M. González-Sánchez ${ }^{1}$, A.I. Cuesta-Vargas ${ }^{1,2}$ \\ ${ }^{1}$ Department of Physiotherapy and Psychiatry, University of Malaga, Spain \\ ${ }^{2}$ School of Clinical Science, Faculty of Health Science, Queensland University Technology, Australia
}

Abstract- Study Design: cross-sectional study. Objectives: to compare erector spinae (ES) muscle fatigue between chronic non-specific lower back pain (CNLBP) sufferers and healthy subjects from a biomechanical perspective during fatiguing isometric lumbar extensions. Background: paraspinal muscle maximal contraction and fatigue are used as a functional predictor for disabilities. The simplest method to determine muscle fatigue is by evaluating the evolution during specific contractions, such as isometric contractions. There are no studies that evaluate the evolution of the ES muscle during fatiguing isometric lumbar extensions and analyse functional and architectural variables. Methods: In a pre-calibrated system, participants performed a maximal isometric extension of the lumbar spine for 5 and 30 seconds. Functional variables (torque and muscle activation) and architecture (pennation angle and muscle thickness) were measured using a load cell, surface electromyography and ultrasound, respectively. The results were normalised and a reliability study of the ultrasound measurement was made. Results: The ultrasound measure- 
ments were highly reliable, with Cronbach's alpha values ranging from 0.9510 .981 . All measured variables shown significant differences before and after fatiguing isometric lumbar extension. Conclusion: During a lumbar isometric extension test, architecture and functional variables of the ES muscle could be analised using ultrasound, surface EMG and load cell. In adition, during an endurance test, ES muscle suffers an acute effect on architectural and functional variables..

Keywords- Ultrasound, EMG, Torque, Fatigue, 


\section{INTRODUCTION}

The erector spinae (ES) muscle is mainly responsible of lumbar extension, also contributing to the lateral tilt of the trunk and maintenance of posture [1]. These functions should serve as motivation for further study of this important muscle in the lower back.

The lower back is the area that has been proven most prone to fatigue in efforts requiring lumbar extension (more so than the upper back, hamstrings and buttocks) [2].

A comprehensive study of the muscular strength and endurance specific to the lumbar region could be very relevant for understand the behavior of the main extension lumbar muscle [3].

Neuromuscular fatigue is considered a very complex phenomenon that is due to several causes: central fatigue, fatigue of the neuromuscular junction and muscle fatigue [4]. Muscle fatigue has been defined as the state that temporarily limits the ability to produce work to a certain intensity caused by the work itself $[5,6]$ or as any exercise that causes a reduction in the maximum capacity to generate force or power. One of the easiest ways to determine muscle fatigue is to assess the evolution of the work over a specific time through isometric contractions, ergonomically supported loads, etc. [3]. These two variables, maximum strength and muscular endurance have been used as predictors of disability in musculoskeletal pathologies $[7,8]$.

In biomechanics, ultrasound has been used to assess morphological changes in muscle thickness [8-12], muscle fibres [13-15], pennation angle $[16,17]$ and 
even the cross-sectional area $[18,19]$. Studies have shown that the reliability of ultrasound in the paraspinal muscles varies between moderate and excellent at presenting intraclass correlation index values ranging between 0.72 and 0.98 [20].

Local monitoring of muscle is possible using surface electromyography (sEMG) $[2,21]$. These analytical instruments have expanded greatly in recent years because of the advantages they possess, including being noninvasive, they can be applied in situ, they allow monitoring of changes in muscle activation (surface electromyography) when the muscle performs defined work, they are instruments with high reliability, they can focus on a particular muscle, and they are relatively inexpensive compared with other analysis tools [21].

No studies have been found that describe the response of the ES muscles after MVC and a fatigue test during isometric lumbar extension using SEMG and ultrasound simultaneously as measuring instruments to extract architectural and functional variables.

The objective of this study was to describe and to analyze architectural variables (muscle thickness and pennation angle) and functional aspects (muscle activation and torque) of ES muscle when performing a muscular endurance test and maximal voluntary contraction during isometric lumbar extension. 


\section{MATERIALS AND METHODS}

A. Design

Cross-sectional study, which analyses the response of the ES muscle during maximal isometric contraction of 5 and 30 seconds duration on a pre-calibrated system.

Participants: Participants: The criteria for inclusion were that subjects were adults aged between 18 and 65 years. The criteria for exclusion were pain in the nerve root/radicular pain, $\mathrm{BMI} \geq 35$, infection, neoplasms, metastases, osteoporosis, arthritis, scoliosis or any asymmetry evident in the spinal column, pregnancy, cognitive impairment from any cause and inability to complete the proposed exercise.

All subjects signed an informed consent, stating that they had received a careful explanation of the purpose and design of the study.

The study was approved by the Tribunal of Review of Human Subjects at the University of Malaga. Data were handled in accordance with the ethical standards of the Helsinki Declaration of 1975, as revised in 2000 [22].

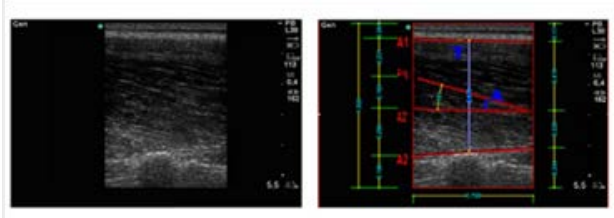

Figure 1: example of architecture variables measured from ultrasound image. 


\section{B. Procedure}

a) Electromyographic record.

Two bipolar surface electromyography sensors (Datalog Biometrics, England) were placed bilaterally. Each sensor has two electrodes separated by one centimetre. The skin was sterilised with alcohol and a neutral adhesive specifically designed to adhere the sensor was used.

EMG was collected from the ES muscle group, placing the sensor $2 \mathrm{~cm}$ lateral from the line of the spinous processes at L3-L4 level.

EMG was sampled at $1000 \mathrm{~Hz}$ (Datalog Biometrics, England) and analysed using a customised Datalink 3.0 programme. Before processing the signal, a low pass filter was used ( $1 \mathrm{kHz}$ cutoff frequency) to reduce high frequency noise.

\section{b) Ultrasonography record.}

Architectural variable (thickness and pennation angle) measurements were made from the ES muscle ultrasound pictures.

The ultrasound machine used (SonoSite M-Turbo, SonoSite Inc., Bothell, WA, USA) has a linear translator and a frequency range of $613 \mathrm{MHz}$ for ultrasound imaging. The head used was $5 \mathrm{~cm}$ wide. The image had a depth of $6.5 \mathrm{~cm}$. The measurements were taken bilaterally, placing the head at the level of $L_{3}-L_{4}$, at 3 $\mathrm{cm}$ from the line of the spinous processes. Each ultrasound image was analysed to obtain the two muscle architecture variables considered in this study: pennation angle and thickness. An example is shown in Figure 1. 


\section{c) Torque record.}

To record the torque of each participant, a computerised load cell (Real Power, Globus Italia) was positioned between two chains. One chain was placed on the arm of the machine that guided the gesture on which the subject would push during the execution of movement, while the other was fixed to the wall in front of the machine where the test was being run.

The angles between the chain and the thrust direction and between the chain and the floor were zero at the time of the isometric contraction.

\section{Experimental protocol}

Each participant was placed in the precalibrated machine with invincible resistance (figure 2). A chain, in the middle of which was placed a load cell (computerised Real Power, Globus, Italy), was used to measure the torque created by the participant during the test execution. The participant then performed three MVCs for $5 \mathrm{~s}$, with two minutes rest between each execution. Each subject could freely practice the movement before the MVCs and equivalent verbal encouragement was given to all participants. During the execution of the three maximum isometric contractions, electromyographic, ultrasound and torque (using the load cell) recordings were taken. The maximum value recorded after

three repetitions was considered the value of the MVC and served as a reference for normalisation of the values recorded later in the fatigue test. 


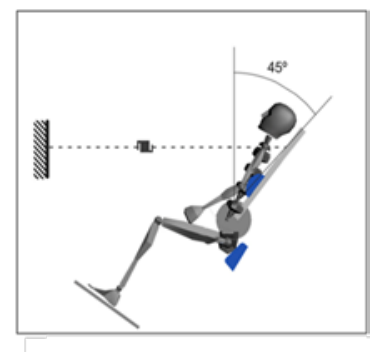

Figure 2: scheme of the subject's position and ejecution of the gesture analised.

For the fatigue test, the same protocol was repeated increasing the time up to 30 seconds the maximum isometric extension and up to 240 seconds the rest time between repetitions. During this test, the differences in the variables considered in this study (muscle activation, force moment, muscle thickness and pennation angle) were calculated from measurements taken at the beginning and end of the test. Before being analysed, the data were treated as and then normalised based on the MVC.

The subject performed the execution of maximal isometric extensions, at $45^{\circ}$ from the vertical with the lumbar spine in a neutral position. The thighs and hips were attached to the machine by straps. A position execution scheme of the maximum isometric extension is shown in Figure 1.

\section{d) Data analysis.}

The analysis consisted of a descriptive analysis of each variable and a calculation of the mean difference, between pre and post values recorded during endurance test, by Student's t test for independent data. 
For each architecture variable, the three measures taken during MVC isometric contraction were used to calculated the internal consistency (Cronbach's alpha) of the measure, together with the $95 \%$ confidence interval.

For statistical analysis, the Statistical Package for Social Sciences program (SPSS; version 17.0 for Windows; Illinois, USA) was used.

\section{RESULTS}

The participants were 46 healthy subjects ( 21 men and 25 women). The mean age was 30.39 years $( \pm 7.79)$, average height $170.52 \mathrm{~m}( \pm 16.93)$, average weight $73.59 \mathrm{~kg}( \pm 21.20)$ and body mass index (BMI) $23.68( \pm 3.15)$.

Table 1 shows the main values of the functional and architectural variables during the MVC for 5 seconds.

Table 1. results variables of MVC for $5 \mathrm{sec}$

\begin{tabular}{|c|c|}
\hline & $\begin{array}{l}\text { MEAN } \\
\text { (SD) }\end{array}$ \\
\hline Torque $(\mathrm{N} \cdot \mathrm{m})$ & $62.26( \pm 19.47)$ \\
\hline Angle Right $\left({ }^{\circ}\right)$ & $13.67( \pm 2.29)$ \\
\hline Angle Left $\left(^{\circ}\right)$ & $12.65( \pm 2.19)$ \\
\hline $\begin{array}{l}\text { Thickness Right } \\
\text { (mm) }\end{array}$ & $30.6( \pm 6.1)$ \\
\hline $\begin{array}{l}\text { Thickness } \\
\text { (mm) }\end{array}$ & $31.2( \pm 5.9)$ \\
\hline $\mathbf{N}$ & 46 \\
\hline
\end{tabular}


Table 2 shows the difference between variables at the start and end the test. These results were normalised to the MVC, so the difference could be represented as a percentage change in the variable. It could be observed that functional and architectural variables underwent significant changes during the execution of the test.

Table 2. Differences between the start and end of the fatigue test

\begin{tabular}{|c|c|c|c|c|}
\hline & \multicolumn{4}{|c|}{ Healthy Subjects } \\
\hline & \multirow[t]{2}{*}{$\begin{array}{l}\text { Mea } \\
\mathrm{n}\end{array}$} & \multicolumn{2}{|c|}{$\mathrm{Cl}(95 \%)$} & \multirow[t]{2}{*}{$\begin{array}{c}\text { Sig. } \\
\text { (bilateral) }\end{array}$} \\
\hline & & Sup & Inf & \\
\hline Torque $(\mathrm{N} \cdot \mathrm{m})$ & 0.20 & 0. & 0.2 & 0.000 \\
\hline $\begin{array}{l}\text { Pennation An- } \\
\text { gle }\left(^{\circ}\right)\end{array}$ & 0.47 & $\begin{array}{r}0 . \\
44\end{array}$ & $\begin{array}{r}0.5 \\
1\end{array}$ & 0.000 \\
\hline $\begin{array}{l}\text { Muscle Thick- } \\
\text { ness }(\mathrm{cm})\end{array}$ & 0.18 & $\begin{array}{r}0 . \\
16\end{array}$ & $\begin{array}{r}0.2 \\
0\end{array}$ & 0.000 \\
\hline $\begin{array}{l}\text { Muscle Activa- } \\
\text { tion (mV) }\end{array}$ & 0.21 & $\begin{array}{r}0 . \\
18\end{array}$ & $\begin{array}{r}0.2 \\
5\end{array}$ & 0.000 \\
\hline
\end{tabular}

The results after the reliability test performed on thickness and pennation angle (architectural variables) showed a very high stability measure, with Cronbach's alpha values for right angle $0.951(95 \% \mathrm{Cl}$ : $0.920-0.971)$, for left angle $0.981(95 \% \mathrm{Cl}: 0.969-0.989)$, for right thickness $0.969(95 \% \mathrm{Cl}: 0.963-$ $0.981)$ and for left thickness 0.971 (95\%Cl: $0.966-0.978)$. 


\section{DISCUSION}

To our knowledge, this is the first study that analised the behavior of the ES muscle when performing a maximal voluntary contraction and an endurance test of lumbar extension, using sEMG, ultrasound and load cell simultaneously.

We also did not find studies measuring the angle of muscle pennation. Some studies have measured the thickness of this muscle using the same method as that employed here (placing the head longitudinally to the muscle) $[23,24]$. Despite placing the head in the same way and taking measurements at the same point of the lumbar spine $\left(L_{3}\right)$, the average values obtained in the two studies differed from those observed by us.

The ES average thickness values on the right and left, $30.6 \mathrm{~mm}( \pm 6.1)$ and $31.2 \mathrm{~mm}( \pm 5.9)$, respectively, were different from the corresponding values observed in the study by Watanabe et al. [23], where the value was $33.9 \mathrm{~mm}$ ( \pm 8.4), and Masuda et al.[24], where the mean was $39.4( \pm 4.2 \mathrm{~mm})$. One explanation for the difference could be found at the position of the subjects when the ultrasound image was recorded. Participants in the studies of Watanabe et al [23] and Masuda et al. [24] were in full lumbar extension, whereas in our trial, they stopped $45^{\circ}$ from the vertical. The authors of the other two studies obtained the same trend of, starting from a position of maximum flexion, muscle thickness increasing progressively as it approached its maximum extension position, where the highest muscle thickness was recorded.

No studies were found that uses ultrasound as a method to analyse the changes undergone by the ES muscle during a fatigue test. However, several 
studies have demonstrated by ultrasound the acute effects of muscular fatigue in the biceps brachii [25] and the vastus lateralis due to fatigue $[26,27]$. They show what appears to be muscle fatigue, with the muscle architecture parameters considered in this study (pennation angle and thickness) showing a significant decrease after the test.

\section{CONCLUSION}

During a lumbar isometric extension test, architecture and functional variables of the ES muscle could be analised using ultrasound, surface EMG and load cell. In adition, during an endurance test, ES muscle suffers an acute effect on architectural and functional variables. 


\section{REFERENCES}

1. Bogduk, N., Macintosh, J.E., Pearcy, M.J. (1992) A universal model of the lumbar back muscles in the upright position. Spine 17, 897-913.

2. Larivière $C$, da Silva RA, Arsenault $A B$, et al. (2010) Specificity of a back muscle exercise machine in healthy and low back pain subjects. Med Sci Sports Exerc Mar;42(3):592-9.

3. Larivière $\mathrm{C}$, Bilodeau M, Forget $\mathrm{R}$, et al. (2010) Poor back muscle endurance is related to pain catastrophizing in patients with chronic low back pain. Spine (Phila Pa 1976) 35(22):E1178-1186.

4. Merletti R, Rainoldi A, Farina D. (2004) Myoelectric manifestations of muscle fatigue. In: Merletti R, Parker P, eds. Electromyography-Physiology, Engineering, and Noninvasive Applications, New Jersey, USA: John Wiley \& Sons, Inc 233-258.

5. Heimer S. Fatigue. (1987) In: Medved R, ed., Sports Medicine, second ed 147-151.

6. Vollestad NK. (1997) Measurement of human muscle fatigue. J Neurosci Meth 74(2):219-227.

7. Granacher U, Gruber M, Gollhofer A. Force production capacity and functional reflex activity in young and elderly men. Aging Clin. Exp. Res. 2010; $22: 374-382$

8. Biering-Sorensen F. (1984) Physical measurements as risk indicators for low-back trouble over a one-year period. Spine 9(2):106-19. 
9. Luo X, Lynn George M, Kakouras I, et al. (2003) Reliability, validity and responsiveness of the short form 12-item survey (SF-12) in patients with back pain. Spine (Phila Pa 1976) 1:1739-45.

10. Morse $\mathrm{Cl}$, Thom JM, Birch KM, et al. (2005) Changes in triceps surae muscle architecture with sarcopenia. Acta Physiol Scand 183(3):291-298.

11. Narici M, Maganaris C. (2006) Muscle architecture and adaptations to functional requirements. In Bottinelli R, Reggiani C, eds. Skeletal Muscle Plasticity in Health and Disease. Amsterdam, The Netherlands: Springer 265288.

12. Visser M, Goodpaster BH, Kritchevsky SB, et al. (2005) Muscle mass, muscle strength, and muscle fat infiltration as predictors of incident mobility limitations in well-functioning older persons. J Gerontol A Biol Sci Med Sci 60(3):324-333.

13. Okita M, Nakano J, Kataoka H, et al. (2009) Effects of therapeutic ultrasound on joint mobility and collagen fibril arrangement in the endomysium of immobilized rat soleus muscle. Ultrasound Med Biol 35, 237-44.

14. Maganaris CN. (2001) Force-length characteristics of in vivo human skeletal muscle. Acta Physiol Scand, 172, 279-85.

15. Ichinose $Y$, Kawakami $Y$, Ito $M$, et al. (1997) Estimation of active forcelength characteristics of human vastus lateralis muscle. Acta Anat 159, 78 83.

16. Kawakam Y, Abe T, Fukunaga T. (1993) Muscle-fiber pennation angles are greater in hypertrophied than in normal muscles. J Appl Physiol 74, 2740-4. 
17. Mahlfeld K, Franke J, Awiszus F. (2004) Postcontraction changes of muscle architecture in human quadriceps muscle. Muscle Nerve, 29, 597-600.

18. Kanehisa H, Ikegawa S, Tsunoda $\mathrm{N}$ et al. (1999) Strength and crosssectional areas of reciprocal muscle groups in the upper arm and thigh during adolescence. Int J Sports Med 16, 54-60.

19. Narici MV, Binzoni T, Hiltbrand E, et al. (1996) In vivo human gastrocnemius architecture with changing joint angle at rest and during graded isometric contraction. J Physiol-London, 496, 287-97.

20. Stokes M, Hides J, Elliott J, et al. (2007) Rehabilitiative ultrasound imaging of the posterior paraspinal muscles. JOSPT 37(10), 581-595.

21. Cifrek M, Medved V, Tonković S, et al. (2009) Surface EMG based muscle fatigue evaluation in biomechanics. Clin Biomech (Bristol, Avon). 24(4):327-40.

22. Declaracion De Helsinki De La Asociacion Medica Mundial - principios éticos para las investigaciones médicas en seres humanos [homepage on the Internet]. [cited 11/5/2009]. http://www.wma.net/es/30publications/10policies/b3/index.html. Accessed 21 May, 2012.

23. Watanabe K, Miyamoto K, Masuda T, et al. (2004) Use of ultrasonography to evaluate thickness of the erector spinae muscle in maximum flexion and extension of the lumbar spine. Spine (Phila Pa 1976). 29(13):1472-1477.

24. Masuda T, Miyamoto K, Oguri K et al. (2005) Relationship between the thickness and hemodynamics of the erector spinae muscles in various lumbar curvatures. Clin Biomech (Bristol, Avon) 20(3): 247-53. 
25. Shi J, Zheng YP, Huang QH, et al. (2008) Continuous monitoring of sonomyography, electromyography and torque generated by normal upper arm muscles during isometric contraction: sonomyography assessment for arm muscles. IEEE Trans Biomed Eng Mar;55(3):1191-1198.

26. Brancaccio P, Limongelli FM, D'Aponte A, et al. (2008) Changes in skeletal muscle architecture following a cycloergometer test to exhaustion in athletes. J Sci Med Sport 11(6):538-541.

27. Csapo R, Alegre LM, Baron R. (2011) Time kinetics of acute changes in muscle architecture in response to resistance exercise. J Sci Med Sport 14(3):270-274 